\title{
Process Parameter Research on AZ31 Magnesium Alloy Profile Expanding Extrusion Process
}

\author{
Rui Wang \\ Mechanical Engineering College, Linyi University, Linyi, Shandong 276005, P. R. China \\ Wangrui200499@163.com
}

\begin{abstract}
Key words: Magnesium; Expanding; Extrusion; Process Parameters; AZ31
Abstract: Process parameters of AZ31 Magnesium alloy profile expanding extrusion are researched, such as extrusion temperature, extrusion speed, deformation degree, etc., and AZ31 Magnesium alloy profile expanding extrusion are implemented. Extrusion speed and production yield are effective elevated by effective control of extrusion temperature, extrusion speed and deformation degree. This research has a major theoretical breakthrough and practical significance for Magnesium alloy profile expanding extrusion technology.
\end{abstract}

\section{Introduction}

Magnesium alloy is the lightest metal structure materials currently available applications, excellent specific rigidity, shock resistance, thermal conductivity, electromagnetic shielding to become the new darling of aerospace, modern automobile manufacturing, civil engineering and other fields, is the most competitive potential of new structural materials[1]. At present, the domestic spread extrusion technology more concentrated in aluminum profiles [2-9], and magnesium alloy extrusion profiles broadened research has not been reported. Magnesium alloy extrusion profiles broadened still in the early and exploratory stage, with the manufacturing of lightweight, energy-saving and environmental protection requirements increase, market research and development of the urgent requirement of magnesium alloy profiles spread extrusion technology.

Extrusion temperature, extrusion speed and extent of deformation of magnesium alloy extrusion production process in three key parameters. Extrusion temperature, speed control is not good, are easy to cause the metal to flow unevenly, metal surface tensile strength decreased, with increased tensile stress and cracks; in the magnesium alloy extrusion profiles broadened, since the wall thickness is inconsistent profiles, extrusion, so higher extrusion parameters setup requirements than small paper in Shandong charges County silver Magnesium Co., AZ31 magnesium alloy extrusion plant be spread extrusion temperature profiles, extrusion speed and the degree of deformation studies, Linqu Aluminum Co., Ltd. Yangtze River were AZ31 magnesium alloy extrusion profiles broadened. Through a large number of engineering practice to extrusion temperature, extrusion speed and extent of deformation of effective control, effectively improve the extrusion rate and yield, the magnesium alloy profiles spread extrusion technology has major theoretical breakthrough and practical significance.

\section{Extrusion temperature studies}

Width of magnesium alloy extrusion profiles, the extrusion temperature is the most basic and most crucial technological factors. Extrusion Temperature on product quality, productivity, tool life, energy consumption and so have a huge impact. Extrusion The biggest problem is to control the 
temperature of the metal, from the start of heating to extrusion ingot entire process must ensure that the organization is not soluble phase separation or precipitation of small particles dispersed presented from solid solution.

In general, the maximum ductility magnesium alloy in the temperature range of $350-400^{\circ} \mathrm{C}$ for AZ31 magnesium alloy extrusion billet heating temperature is set to $380^{\circ} \mathrm{C}$, the heating temperature reached after holding 15-30min. Magnesium alloy billets heated in an electric furnace, furnace with forced air circulation system to maintain temperature uniformity, the furnace temperature does not exceed $\pm 10^{\circ} \mathrm{C}$, furnace temperature thermocouple measurement; thermocouple mounted at a distance of 100-150 mm blank ; automatically adjust the oven temperature measuring instruments to ensure accuracy in the furnace installation within $\pm 8^{\circ} \mathrm{C}$.

Extrusion billet removed surface oil, magnesium shavings, burrs and other dirt. When heated magnesium alloy, it must be strictly done in a furnace without the magnesium alloy contact with the heating element, so that a certain distance apart. And heating furnace magnesium alloy, beside their resistance wire fitted with a protective plate to avoid overheating and cause a fire. Billet should be evenly placed on the hearth, to maintain a certain interval. Front loading, first preheat the oven to a predetermined temperature $\left(380^{\circ} \mathrm{C}\right)$, because the high thermal conductivity of magnesium alloy, which can shorten the heating time and avoid grain growth.

\section{Mold preheating studies}

Magnesium alloy deformation temperature range is narrow, good thermal conductivity, will produce quenched encounter cold mold and cracks. So before you want to spread extrusion die preheating, whose role is to reduce the temperature difference between the mold and the billet contact, so that when the extrusion billet into the billet mold cooling will not be too large so that the plastic lower deformation resistance increases; while avoiding the billet surface and the center layer temperature is too large, so uneven deformation increases, as well as causing damage to the extrusion and mold. Since the billet and the mold contact area, the contact time is long, and during the extrusion process causes the thermal effect due to the deformation of mold temperature, the mold must be heated to a temperature slightly lower than the billet, designed so that the preheating temperature of the mold $280^{\circ} \mathrm{C}$.

\section{Extrusion speed studies}

Influence of extrusion speed and plastic deformation resistance depends on the shear strain (or hardening) and softening process (recovery and recrystallization) the interrelationship between. When high extrusion speed, due to deformation caused by thermal effects, will raise the temperature of the extrusion billet, thereby significantly reducing the flow stress; when the extrusion rate increased again, although billet heating obvious, but due to the deformation metal hardening process faster than the recrystallization process of softening speed, the flow stress of the blank will be significantly increased.

Thus magnesium alloy extrusion profiles broadened process must be carefully controlled extrusion speed. Extrusion speed thermal effects on the deformation, deformation uniformity, recrystallization and solution process, profiles mechanical properties and surface quality have an important effect profiles. Squeeze too fast, there will be a tendency profile surface pitting, cracks 
and so on; at the same time, increasing the metal deformation nonuniformity. AZ31 magnesium alloy extrusion rate is particularly sensitive, and therefore should not be higher extrusion speed extrusion molding, extrusion magnesium alloy profiles wide speed to $0.8 \mathrm{~m} / \mathrm{min}$. During extrusion billet at the temperature deformation zone is varied, with the completion of the extrusion process, the temperature gradually increased deformation zone, and with the increase extrusion speed increases. Therefore, in order to prevent cracking the extrusion, the extrusion process is carried out with the deformation zone and the temperature rises, the extrusion rate should be decreased.

\section{Lubricant studies}

In order to reduce friction billet and extrusion cylinder and die work belt between the mold to prevent sticking and reduce friction to facilitate metal flow, you must use a lubricant for lubrication. Lubricants can also play a role in heat insulation, thereby improving die life. Width magnesium alloy extrusion profiles are used in the production of glass lubricant.

Glass lubricant has the following advantages:(1) The insulation is good, so that the die life and prevent the blank is rapidly cooled.(2) to improve extrusion ratio.(3) does not generate by carbon phenomenon.(4) pressing surface can be kept clean.(5) at the operating temperature of the glass into a tacky state, it is possible to continue to be lubricated through the die gap. This means you can squeeze a long time, thereby increasing production efficiency.(6) when the extrusion profiles and hollow sections can be obtained relatively clear angular shape.

\section{Width extrusion process studies}

Based on the research of magnesium alloy profiles spread extrusion process parameters described above, in order to better plastic extruded AZ31 magnesium alloy ingot, at $380^{\circ} \mathrm{C}$ when using magnesium alloy extrusion profiles were broadened, extrusion billet heating field shown in Fig.1. Mold preheating temperature ranges from $280^{\circ} \mathrm{C}$, mold heating field shown in Fig.2. Designed for extrusion speed $0.8 \mathrm{~m} / \mathrm{min}$, magnesium alloy extrusion profiles broadened the field as shown in Fig.3. Extruded magnesium alloy to produce the wide profiles shown in Fig.4. As can be seen from the figure, magnesium alloy extruded profiles wide deformation uniform, smooth surface, no pitting, cracks and other tendencies, products reached a very high level of quality.

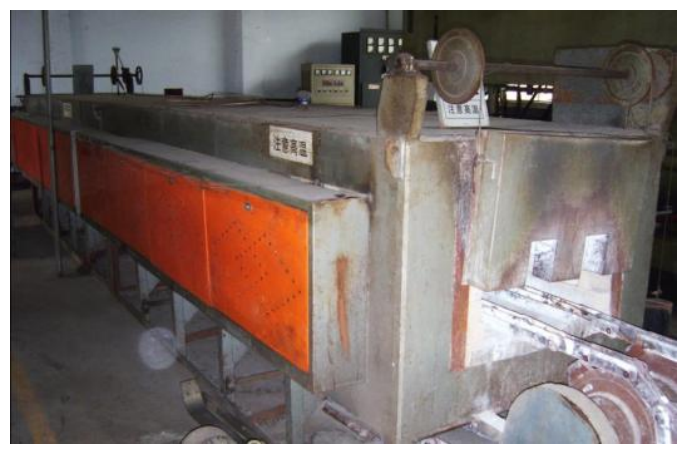

Fig. 1 The scene of extrusion billet heating

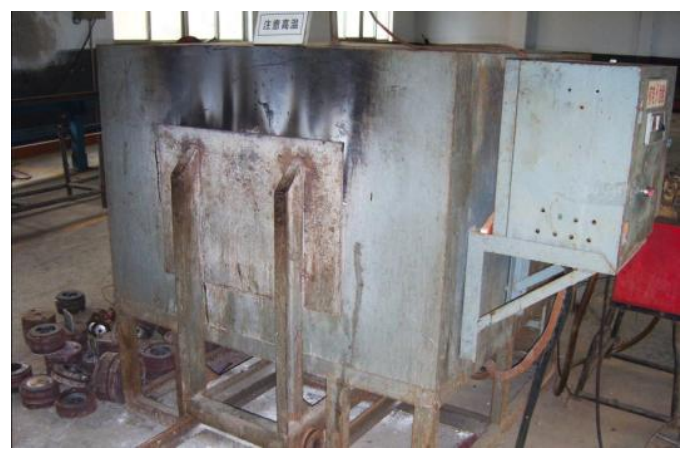

Fig.2 The scene of die heating 

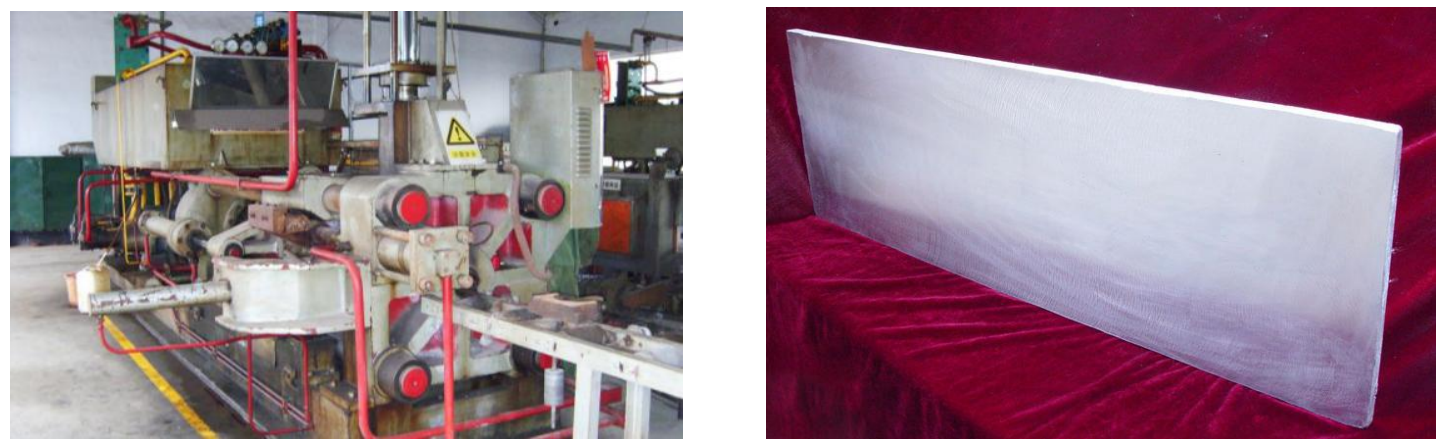

Fig.3 The scene of expanding extrusion process Fig.4 The extra-wide magnesium alloy profile

\section{Summary}

Practical results show that: extrusion temperature, speed and extent of deformation are three main arguments wide magnesium alloy profile extrusion process, the extrusion temperature, speed control is not good, are easy to cause the metal to flow unevenly, the tensile strength of the metal surface decline, with a tensile stress increases and cracks; in the wide profile extrusion processing, Based on the extrusion temperature, extrusion speed and extent of deformation control, effectively improve the extrusion rate and yield, and come to the following in conclusion:

(1) Based on the $380^{\circ} \mathrm{C}$ when AZ31 magnesium alloy extrusion profiles were broadened, at this temperature plasticity AZ31 magnesium alloy has the best success of the extrusion temperature control, to ensure that the phase structure of the metal is not soluble precipitation or present small particles from solid solution dispersed precipitated.

(2) AZ31 magnesium alloys with the die during extrusion temperature rise reduces fluidity, the mold must be heated to a temperature slightly lower than the billet, designed for mold preheating temperature $280^{\circ} \mathrm{C}$.

(3) squeeze too fast, there will be a tendency profile surface pitting, cracks, etc., increased metal deformation nonuniformity. Wide magnesium alloy extrusion profiles designed for speed 0.8 $\mathrm{m} / \mathrm{min}$.

(4) AZ31 magnesium alloy extrusion profiles broadened Lubricate the use of glass, reducing friction billet and extrusion cylinder and die work belt between the mold to prevent sticking and reduce friction, improve metal flow.

\section{Acknowledgements}

This research work is supported by Science Foundation of Shandong Province (No. ZR2012EEL12) and Science and technology development project of Shandong Province (No. 2011GGA13044)

\section{References}

[1] Yongxin Luo, Hua Long, Laixi Zhang. Hot Work Technology, Vol.39(2010), p38-42.

[2] Rui Wang. Applied Mechanics and Materials, Vol.778(2015), p116-119.

[3] Hailin Tan. Hot Work Technology, 2011, Vol.40(2011), p124-129.

[4] Rui Wang. Advanced Materials Research, Vol.418-420 (2011), p2012-2105

[5] Rui Wang. Advanced Materials Research, Vol. 189-193 (2011), p1749-1752.

[6] Rui Wang. Advanced Materials Research, Vol. 97-101 (2010), p400-403. 
[7] Yanfen Wang, Ji Xiong, Zhiyuang Wang. Hot Work Technology, 2009, Vol.38(2009), p81-87.

[8] G. Fang, J. Zhou, J. Duszczyk. Journal of Materials Processing Technology, Vol.199 (2008), p. 91.

[9] S.M. Lou, G.Q. Zhao, R. Wang, X.H. Wu. Journal of Materials Processing Technology, Vol.206 (2008), p 481. 